\title{
Study and Practice of First-class Course Construction
}

\author{
Hengwu Li * \\ School of computer science and technology, Shandong University of finance and economics, Jinan, China, 250014 \\ ${ }^{*}$ Corresponding author. Email: hengwu@sdufe.edu.cn
}

\begin{abstract}
The theoretical basis of creating first-class lessons is expounded, and the challenges and innovative opportunities of creating first-class lessons are discussed from ideological consensus, teachers' quality, professional system, curriculum class, technical means, assessment mechanism and cooperation mechanism, etc. Finally, the practice and application of the first-class curriculum construction from the aspects of design concept, content reform, method reform, mixed teaching reform, practice reform and assessment reform are showed.
\end{abstract}

Keywords: Talent training, Theory, Mechanism, Practice, Application.

\section{INTUODUCTION}

Curriculum is the basic teaching unit and the main carrier of personnel training. The first-class curriculum organically integrates students' knowledge, ability, thinking and accomplishment, which is the focus of teaching reform. The construction of first-class courses is based on many theoretical foundations

\subsection{Learning Pyramid Theory}

Learning pyramid theory shows the learning effect after two weeks for different ways of learning. The first one is listening which leaves only $5 \%$ of the learning content. The second way is reading, which can retain $10 \%$ of that. The third one, audio-visual learning, can reach $20 \%$ by means of sound and picture. The fourth is "demonstration", which can be learned in the way of "demonstration and observation", and can remember $30 \%$. The fifth is "discussion", which can be learned in the way of "group discussion", and can remember $50 \%$. The sixth is "practice", learning by doing or practicing, which can remember $75 \%$. The seventh way is "teach others" or "apply right away", which can remember $90 \%$.

The traditional ways with learning effect less than $30 \%$ are individual learning or passive learning; The learning effect of more than $50 \%$ is team learning, active learning and participatory learning. We should pay more attention to the promotion of practice, discussion and application. This is the embodiment of the advanced nature and interaction of the teaching form of first-class.
It's easy to feel it on paper, but you have to practice it. Professional teaching should increase more curriculum design, practice and training, and learn through "doing", "using", "experiencing", "hands-on", "teaching", "discussion" and "cooperation"1.

\subsection{Constructivism Theory}

Constructivism theory emphasizes that learners actively construct knowledge, learners construct understanding in their own way, and learning is an interactive process of communication and cooperation. Students are the main body and teachers are helpers and promoters.

Knowledge learning consists of two stages: information transmission and internalization. The traditional teaching carries on the information transmission through the class teaching, after class review carries on the internalization. The creation of first-class class should emphasize the information transmission of active preview before class, the absorption and internalization of in class discussion and interaction, and the timely test of learning effect after class. Students are the main body of learning, discussion and interaction are the main form, and teachers guide, help and promote the achievement of teaching objectives, so as to form students' own knowledge structure $^{2}$.

\subsection{Humanistic Learning Theory}

Humanistic learning theory also advocates autonomous learning and cooperative learning, and pays 
more attention to human self-development, non directive meaning learning, emotional education and creative potential of students.

Science and engineering should pay more attention to students' practical application ability, problem solving ability and research ability. It should be changed from teaching knowledge to cultivating ability and quality. This is the high-level nature of first-class, the organic integration of knowledge, ability and quality.

\subsection{Blended Learning Theory}

Blended learning theory emphasizes the combination of the advantages of traditional learning and network learning, personalized learning and ability training learning, and emphasizes that teachers are the leading and students are the main body ${ }^{3}$.

In order to build first-class course for science and engineering, we should make full use of the advantages of rapid development of information technology and rapid updating of knowledge, and build online first-class course, online and offline first-class course, virtual simulation first-class course and practice first-class course, which reflects the cutting-edge and epochal nature of first-class course.

\subsection{Mastering Learning Theory}

Mastering the learning theory emphasizes the combination of group teaching and individual teaching, emphasizes formative evaluation, and attaches importance to timely feedback, diagnosis and correction in the teaching process, so as to take measures to promote the realization of goals and explore and promote the development potential of students.

The combination of large class teaching and small class discussion can achieve the advantages of group teaching and individual teaching, which reflects the inquiry and personalization of learning results.

\section{CHALLENGE OF BUILDING FIRST-CLASS CLASS}

\subsection{Build Consensus}

The construction of first-class curriculum is a systematic project, which can't be accomplished overnight $^{4}$.

The school management should realize the necessity and difficulty of building first-class course from thought to action, carry out reform from the aspects of funds, resources, educational administration and evaluation. It need propaganda and encouragement, need experience exchange and feedback evaluation.
Teachers need to reinvest a lot of energy, or even push it to a new stage. They need to be prepared from the aspects of training, knowledge, cooperation, psychology, role change, and so on, so as to turn building first-class lessons into teachers' internal motivation.

At the student level, how to change from poor speaking and passive learning to active and active speaking, from "I want to learn" to "I want to learn". The realization of inquiry and personalized learning, the management and cooperation of class, group and team also need guidance, training and cultivation.

\subsection{Teachers' Quality}

To build first-class lessons, higher requirements are put forward for teachers' quality. The role of teachers has been upgraded from imparting knowledge and dispelling doubts to preaching, and teachers have become mentors. From knowledge imparting to thinking education, ability cultivation and quality cultivation, teachers need to improve their own quality, which is a challenge in concept, learning and action.

From teaching to guidance, first of all, teachers' overall grasp of knowledge and in-depth understanding of the details, otherwise. Second, control the classroom, master the rhythm of the classroom. We need to consider personality, heart, emotion, atmosphere and other aspects of personalized, heuristic, inquiry learning.

To build first-class lessons, it is necessary to timely feedback and evaluation, timely collect data, reflect on research, form a spiral mechanism of planning, action, observation, reflection, correction and improvement, and need teachers' reflective consciousness, critical and innovative spirit.

\subsection{Build Professional System}

To build first-class course, we need to study and reform the professional training program, and increase the class hours of course design, practice, training, discussion and practice. This is bound to increase the number of class hours, which will cause problems such as class hours, evaluation and cost.

To build first-class curriculum, it is necessary to reorganize the core competence and quality of professional training, determine the suitable form of first-class curriculum construction, the division, connection and support of curriculum content, and the distribution and cooperation of teachers. It is necessary to study the commonness and individuality of various forms of courses, evaluate, to form a standardized process and mode, and conduct training and guidance ${ }^{5}$. 


\subsection{Build class}

To build first-class lessons, it is necessary to reorganize the knowledge and make the information more orderly, interesting and refined.

To build first-class course, we need to use artificial intelligence to solve the problem of different test data of different people and the correction of subjective questions.

To build first-class lessons requires continuous cooperation and division of labor among teachers. There will be differences in concept, content, method, evaluation and so on. It is also a challenge to solve the differences.

\subsection{Create Technical Means}

To build first-class lessons, we need to create incentive means, timely evaluation and feedback means. We need to create the means to activate the classroom atmosphere. We also need to train the corresponding activity methods and skills for teachers.

To build first-class class, we need to participate, interact, experience, audio-visual, discuss and co create. Science and engineering should innovate in information means. We should use new media methods such as internet media, mobile media and social media, and use the internet plus, internet of things, big data, cloud computing, artificial intelligence, machine learning, virtual reality, face recognition, simulation technology, $3 \mathrm{D}$ display and interaction technology to serve teaching.

\subsection{Build Assessment Mechanism}

The assessment of first-class course should be changed from the final examination results to the course process assessment, from the knowledge assessment to the ability and literacy assessment.

The school needs to reform the evaluation objectives, evaluation standards, evaluation means and evaluation methods, to make a comprehensive, reasonable and objective evaluation, to increase the freedom of teachers and the routine and process of evaluation supervision.

\subsection{Cooperation Mechanism}

To build first-class course, we need the cooperation of platform, school, college, teachers and students, the cooperation of inter school, enterprise, administration and teachers, and the construction of course selection alliance to increase the influence and communication effect of first-class course. It needs regular communication and cooperation, feedback and improvement, and linkage and cooperation mechanism.
In short, building "first-class course" is a long-term, complex and difficult process, which needs to be reformed in terms of ideology, quality, system, curriculum, classroom, evaluation and cooperation. It also needs to establish a long-term mechanism and comprehensively examine all aspects involved in the construction of "first-class course".

\section{PRACTICE AND REFORM}

\subsection{Teaching Philosophy Reform}

The first-class course is a five-in-one teaching and experiment system with innovation and ability as the core, which is student-centered, pre-class self-study, inclass research, after-class practice and learning, practice and innovation, and the combination of value, idea, ability and magic devices. The combination of online and offline, automatic evaluation and interactive communication, teaching and competition, practice and scientific research, education and talent, from teaching knowledge to training ability and quality, is to achieve the organic integration of knowledge, ability and quality.

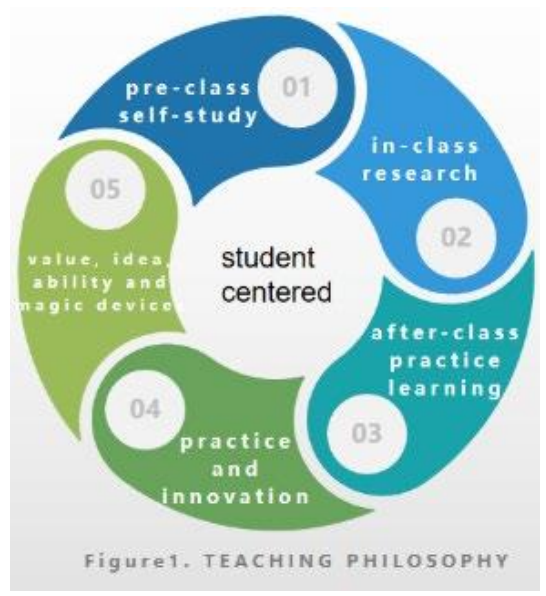

Figure1 Teaching philosophy

\subsection{Curriculum Content Reform}

With the student-centered teaching mode and the ability goal to solve the problem, course content is aggregated and restructured, in accordance with the train thought to solve the problem, cases, verse courseware, in-class quizzes, in-class discussions, units quiz, units tasks, and online test questions, are carefully designed to enhance the refinement of the content,, and meet the needs of hierarchical teaching.

Videos of repeated knowledge explanation, homework correction, key and difficult points that need repeated thinking and learning is made, and online courses is opened. Each video takes 10-20 minutes. It makes full use of the infinite time and space of online learning, chooses the time and place by yourself, stop, 
replay and speed regulation at any time, adapts to the personalized learning, and realizes the lightweight of teachers' work.

To add open, research-oriented, innovative and comprehensive content, the cutting-edge achievements is introduced that of biological information, big data and machine learning into the course, to increase the breadth and depth. It emphasized the organic integration of knowledge, ability and quality, enhanced the high-level nature of the course, highlighted the innovation of the course, and increased the challenge degree of the course.

To expand the breadth, depth and temperature of professional courses, from the perspectives of specialty, industry, country, international, culture and history, the knowledge and humanity of the courses is increased, and enhanced the leading, contemporary and open nature of the courses; the content of ideals and beliefs, research, occupation, rule of law, and moral attainment is increased, to enhance the ability of multiple cognition.

It makes full use of online course learning data, analyzes the learning data with big data, constantly perfects and improves the course content, to realize the informatization of teaching design and the intellectualization of decision-making.

\section{3. Reform of Blended Teaching Process}

The blended teaching reform is carried out to change the weekly class hours to meet the needs of online learning.

Online knowledge videos, documents and knowledge combing, online chapter tests, homework, thinking discussion, simulation tests and Q\&A is made. Before class, students learn videos and documents independently, and conduct tests through knowledge sorting. Groups discussion on the video content, submit the preview report, form students' own knowledge framework through mind mapping, and strengthen the supervision and inspection of

online courses. After class, we can automatically correct chapter tests online and submit homework for automatic evaluation. We answer questions on the platform, WeChat and QQ at any time to absorb and internalize the learning content.

In offline classroom it is made that of knowledge summary and questions answer, classroom exercises, content expansion, group discussion, special lectures and programming competition, to deepen and improve knowledge, cultivate problem-solving ability and higher-order thinking ability. Offline programming practice, training and competition is to cultivate students' practical ability, research and innovation ability and solidarity and cooperation ability. With students as the main body, discussion and interaction as the main form, group thematic discussion as the main form, class dialogue as the auxiliary form, teachers guide, help and promote the achievement of teaching objectives. It gives full play to the group learning atmosphere and teaching effect of offline classroom, and provides new ideas through face-to-face and timely interaction, emotional communication and personality influence, mutual infection and thinking collision.

The combination of online knowledge teaching with offline knowledge internalization, the online duplication works with the offline creation, interactive and emotional communication, the online data with the offline discipline and fair assessment, the online knowledge breadth and the offline knowledge depth, is to realize the knowledge transfer, structure, type, integration, criticism and to explore the study depth.

\subsection{Practice and Inquiry Oriented Reform}

Ability training as the main line, the combination of offline programming practice and online real-time judgement, online competition and offline training, practice and scientific research, is to improve the practice ability and solidarity and cooperation ability, through the "do" school, "with" school, "experience" school, "practice" school, "discussion" school, "cooperation" school.

Online programming assignments are evaluated in real time through the online platform, and are submitted to master the practical level and problems in real time. One assignment provides a variety of choices, which is convenient for students of different levels to practice programming and cultivate in a hierarchical way. Through mutual evaluation of programming assignments, let students compare their programming level, provide students with different ideas, different realization methods, different algorithms and complexity of the same problem, to expand students' ideas and improve their programming level.

The programming homework introduces the test questions competition to increase practicability, competition and interest, and improve students' practical ability. Practical courses are used to guide students to carry out programming training, and special lectures are used to broaden their horizons, so as to improve students' competition level and scientific research innovation ability. Guide the students are conduced to participate in the program design competition and scientific research projects, training and selforganization, to improve the students' teamwork ability, organizational ability and the ability to analyze and solve problems. 


\subsection{Reform of Teaching Modes}

We carry out the reform of blended teaching, explore different teaching modes and ideas, and adopt the pilot and comparison of four teaching modes successively. In the spring of 2019, there was an offline classroom teacher's explanation, and after class, students reviewed summaries, quizzed homework and discussed and answering questions online. In the fall of 2019, students had an online preview, and in the offline class, students explained and summarized, the teachers answered questions. In the spring of 2020, we conducted online preview for students, live interactive classroom summarization, exercises, group discussion, expansion and improvement. In the autumn of 2020, students will preview online, and internalize, discuss and expand offline, and after class, students quizzed homework and discussed and answering questions online.

\subsection{Reform of Teaching Methods}

To improve the teaching effect, we innovation teaching methods. Starting from solving the problem and application, students mainly study by themselves, supplemented by teachers' guidance, pay attention to the personalized development of students, pay attention to ability, self-study and practice, to adapt to diversified needs, interest, communication and guidance. Induction, exploration, change perspective method is used to carry out teaching discussion, interactive teaching, mobilize positive thinking, stimulate learning interest. The combination of online and offline, diversity ways of interact and answer questions with platform, WeChat, QQ, live broadcast, MOOC, to meet the personalized needs of students.

Research learning is carried out to promote the development of students' learning ability. Students are conduced to think positively, to discuss, to arouse interest in learning, and to cultivate consciousness of active learning, research and innovation. Using heuristic, question and answer style, thinking, association, innovation give students inspiration, training of thinking ability.Research-based learning, inquiry-based learning and collaborative learning, special lectures is mad to expand and improve students' logical thinking ability and imagination, exercise students' autonomous learning ability, enhance students' confidence and enhance their ability to challenge themselves.

\subsection{Process Control Reform}

The course assessment method is reformed, from the final exam results to course process assessment, assessment results $=50 \%$ process assessment $+50 \%$ final exam, process examination $=10 \%$ preview report $+50 \%$ MOOC process assessment +40 classroom assessment.
Classroom assessment $=30 \%$ discussion presentation $+20 \%$ exercises $+20 \%$ project report $+30 \%$ comprehensive design.

Students study MOOC videos and document resources, submit preview reports in group cooperation, summarize chapter contents with mind mapping, raise questions and difficulties. teachers review preview reports, and grasp students' learning dynamics in time.

The procedural assessment of MOOC includes chapter tests, thinking discussions, mock exams and practical programming assignments using the automatic evaluation system to deepen the understanding and application of the content.

Group discussion, group comprehensive design, group special report and practice results is introduced into evaluation, to examine scientific thinking and computational thinking, especially examine students' problem-solving ability, team cooperation, innovation ability and comprehensive quality.

We improve the process evaluation system to stimulate learning motivation and professional interest. Tencent live broadcast and classroom interaction is used for chapter summary, Q\&A, practice, group discussion and knowledge expansion, to deepen and improve the content. We enhance students' interest in learning through knowledge concentration, personal customization and adaptive learning, to maximize the teaching quality. Big data is used to help students adjust learning plans and learning methods, so as to realize intelligent teaching process.

Reform course assessment mechanism, from knowledge assessment to ability and accomplishment assessment, to realize the daily and process of assessment supervision. Open, investigative and practical questions are added in the examination to examine the breadth and depth of students' thinking, their problem-solving ability and practical and hands-on ability. The level and quality of the courses are reflected in the teaching evaluation of students on the online platform and in the offline classroom. Open curriculum enables courses and teachers to face social supervision and evaluation, facilitates the intervention of social capital and resources to restructure the knowledge industry chain, and makes knowledge education closer to social needs.

\section{APPLICATION}

In February 2019, the algorithm course launched the on-campus teaching platform. During the course construction, the school provided strong support and guidance in the aspects of project approval, video recording, platform launch, class adjustment, evaluation and assessment, etc. 
It is launched China University MOOC in August 2019. By June 2021, it had served 224 schools with more than 10,000 students. MOOC students in Chinese universities grade the course $4.9 / 5$ points, and students and supervision groups scored 97 points or more in school platform.

In the spring of 2019 offline classes is used. After class, online videos, courseware, tests and homework is deepened. Compared with before the reform in 2018, the average score of students has increased from 71.01 to 74.76. It is mainly through after-class video review and review summary, make up for the shortcomings of offline courses. Using the online platform of automatic evaluation has strengthened the training of students' practical programming and improved their application ability.

It is launched China University MOOC in August 2019, students online preview MOOC videos, and in offline class students summarize, teachers answering questions, after class, students made online test, homework, discuss and answering questions. Compared with teaching offline lectures, students online lesson and answer question, improve the students' initiative and self-consciousness, causes the student to target, the students' average score increased from 74.76 to 78.11 .

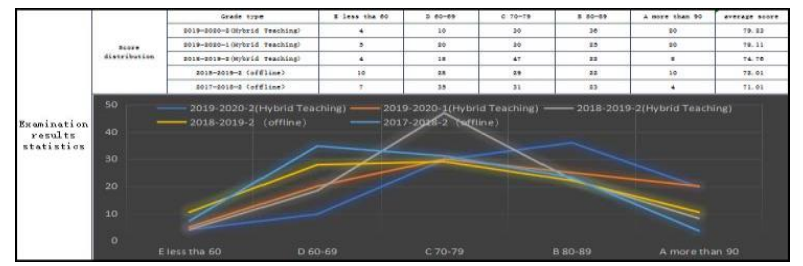

Figure 2 Comparison chart of average grades and fractional proportion of grades for the four semesters

In the spring of 2020 affected by the outbreak, students online preview MOOC and submit preview report, group discussion, practice, development and test, are carried out by live meeting and classroom interaction online, after class homework, discuss, answering questions, to further ensure the quality of student's preview, increase classroom interaction, improve the efficiency of the classroom. Through deepening, expanding and improving, the students' thoughts and horizons were broadened, and their teamwork ability and problem-solving ability were improved. The average score of the students was increased from 78.11 to 79.23 .

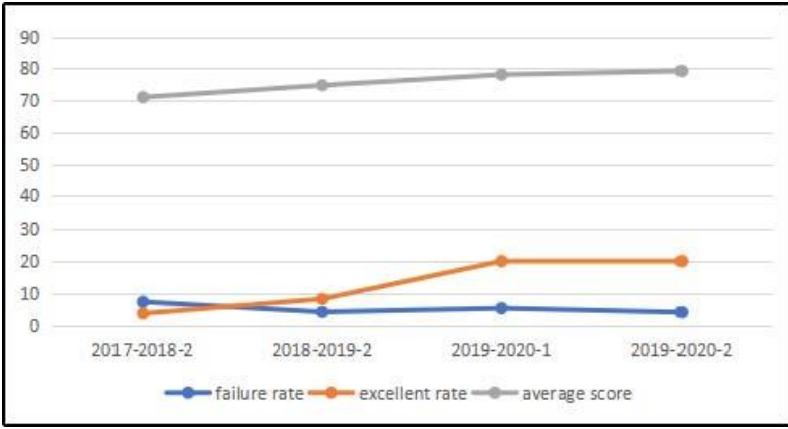

Figure 3 Comparison chart of average grades, failure rate and excellent rate for the four semesters

As can be seen from the figure above, the average score of the four semesters has been gradually improved, while the failure rate has been gradually decreased. The excellent rate has increased from 3.6\% to $19.7 \%$. The peak value of segment proportion gradually increases from $\mathrm{D}$ to $\mathrm{B}$.

By setting up this course, we have guided more than 200 people to participate in various competitions and won more than 100 national and provincial awards. 27 people have been awarded the title of Excellent Instructional Teacher. We have made a historic breakthrough in /ICPC, CCPC and China College Computer Contest.

The algorithm analysis and design won the second prize of Excellent Shared Course in the spring semester of 2020 by Shandong University Curriculum Alliance.

\section{ACKNOWLEDGMENTS}

This work was supported by the grant of Shandong University of finance and economics

\section{REFERENCES}

[1] Wang Ping. On the watershed between gold and water $[\mathrm{N}]$. Chinese Journal of Science and Technology [09-18(004).

[2] Wang Yanru. The Intelligent Teaching Method for the Construction of "Gold Course" in Universities -Principle, Connotation and Framework Design [J]. Innovation and Entrepreneurship Education, 2019, 10(04):112-115.

[3] Ren Meng. "Flip ped Classroom" and Evaluation Feedback [J]. Beijing Education 2019.9,110-112.

[4] Chen Dongchun. Identification of the dual meanings of "gold lesson" to create a connected ecological environment[N]. Chinese Journal of Social Science,2019-08-22(006).

[5] Wu Yan. Building China's "Golden Course" [J]. China University Teaching, 2018 (12). 